\title{
Development and Experimental Investigation of a Marine Vessel Utilizing the Energy Ship Concept for Far Offshore Wind Energy Conversion
}

\author{
Mohd Najib Abdul Ghani Yolhamid, Mohd Norsyarizad \\ Razali, M.N. Azzeri, Mohd Shukri Mohd Yusop, Ahmad \\ Mujahid Ahmad Zaidi, Noh Zainal Abidin
}

The energy ship is a concept for offshore wind energy capture which has received very little attention until today. To this date, there had not been yet an experimental proof of concept. In order to tackle this issue, an experimental platform and data acquisition system has been developed. A 5.5m long sailing catamaran served as a platform equipped with a $240 \mathrm{~mm}$ diameter water turbine. The energy ship platform has been tested several times in the actual river to investigate the workability of the platform and data acquisition system. Results show that energy ship platform can produced 500W electric power for a true wind speed of 10 knots.

\section{KEY WORDS \\ $\sim$ Energy ship \\ $\sim$ Data acquisition system \\ $\sim$ Renewable energy}

Universiti Pertahanan Nasional Malaysia, Kuala Lumpur, Malaysia

e-mail: najib@upnm.edu.my

doi: 10.7225/toms.v10.n02.001

This work is licensed under (cc) BY

Received on: 11.06.2021 / Revised on: 13.10.2021 / Accepted on: 17.10.2021 / Published: 21.10.2021

\section{INTRODUCTION}

Most of the wind energy resource is far out at sea. Unfortunately, it cannot be exploited with current wind energy technologies (grid-connected bottom-fixed or floating wind turbines) due to grid-connection cost, moorings and installation cost, and maintenance cost would be prohibitive. Therefore, there is a need to develop new wind energy technologies in order to enable harvesting the far-offshore wind energy resource.

A solution for this problem is using the energy ship concept which was been proposed by (R. Abd Jamil et. Al.,2019) with greater capacity factor acceding $80 \%$ due to optimizing weather forecast in order to maximizing the capacity factor. An energy ship is a ship driven by the wind using sails and equipped with a water turbine in order to convert the kinetic energy of the ship into electricity. Energy ships include an onboard energy storage system to store the produced energy. This concept is not new since it was first patented by (Salomon,1982). Note that he suggested hydrogen for energy storage. Since then, a few researchers have proposed designs of energy ships (Meller, 2007; Gizara,2007; Kim \& Park, 2010; Pelz et. al.,2016; Gilloteaux \& Babarit, 2017; Ouchi \& Henzi, 2017; Babarit et. al.,2019; Babarit et. al.,2020) as in Figure 1. 

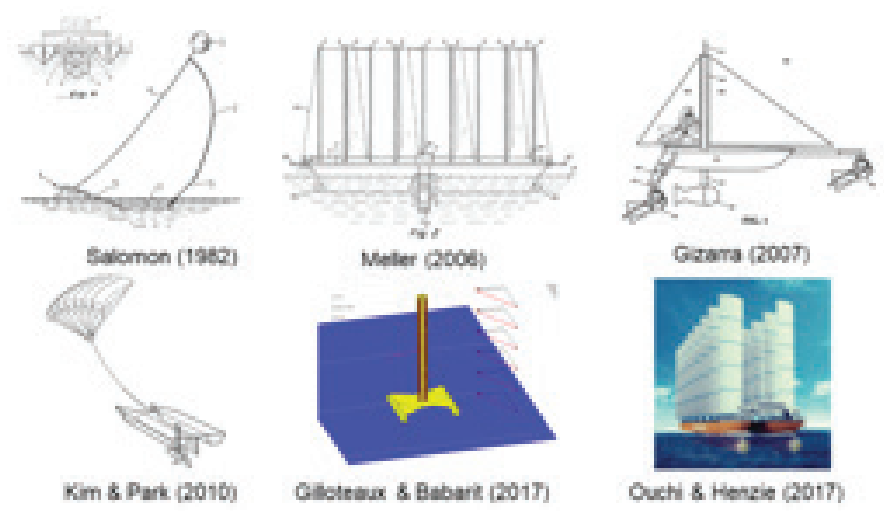

Figure 1.

Various design of energy ship.

The hydro-generators are widely installed in sailing ship as the renewable energy mix provider to accommodate extra power demand for navigational lights, radio, and GPS. For fast sailing ship, the hydro-generator can produced high and stable electricity production as long as the ship is sailing.

The major difference between a sailing ship and an energy ship is the presence of a large water turbine underneath the ship. The main effect of the turbine is to generate an additional drag force. Energy production by the ship depends on the product of this force and the induced velocity in the disk swept by the rotor of the turbine. It has been shown in (Gilloteaux \& Babarit, 2017; Babarit et. al., 2019) that optimizing the drag force and the induced velocity is key to maximize energy production. However, this hasn't been confirmed experimentally yet. Addressing this gap requires the development of an experimental platform, which is one of the aims of the present study. The second aim is to achieve an experimental proof-of-concept for the conversion of wind energy into electricity using the energy ship concept.

\section{DESCRIPTIONS OF THE TEST PLATFORM}

\subsection{Hull and Sails}

In this research, a used Hobie Cat Tiger sport catamaran as in Figure 2 is used as the basis for the test platform. Its length is $5.51 \mathrm{~m}$. It is fitted with a Bermuda rig. The mainsail area is $17 \mathrm{~m}^{2}$, the jib sail area is $3.45 \mathrm{~m}^{2}$ and the spinnaker sail area is $19 \mathrm{~m}^{2}$. This ship is normally operated by a crew of 2 people. Other main characteristics are given in Table 1.

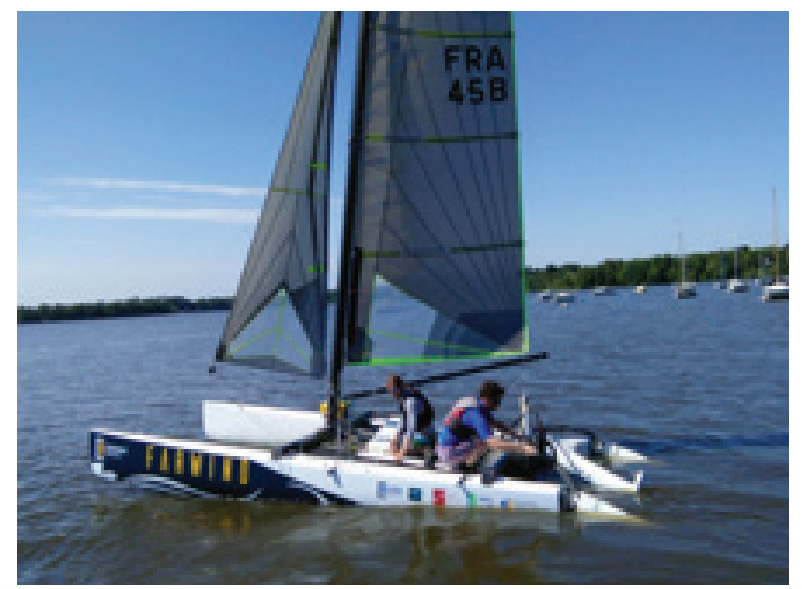

Figure 2.

Picture of a hobie Cat Tiger Catamaran.

Table 1.

Hobie Cat Tiger specification.

\section{Specifications}

\begin{tabular}{ll}
\hline Crew & $2-3$ \\
\hline Length & $5.51 \mathrm{~m}$ \\
\hline Beam & $2.60 \mathrm{~m}$ \\
\hline Capacity & $240 \mathrm{~kg}$ \\
\hline Weight & $180 \mathrm{~kg}$ \\
\hline Draft w /Rudder Up & $0.18 \mathrm{~m}$ \\
\hline Mast Length & $9 \mathrm{~m}$ \\
\hline Mainsail Area & $17 \mathrm{~m}^{2}$ \\
\hline Jib Sail Area & $3.45 \mathrm{~m}^{2}$ \\
\hline Spinnaker Sail Area & $19 \mathrm{~m}^{2}$ \\
\hline Hull Construction & Fiberglass/ foam Sandwich \\
\hline
\end{tabular}

\subsection{Selection of the water turbine}

In order to select the water turbine, an estimation of the power that can be absorbed by the platform for typical wind conditions if true wind speed $W$ is 10 knots (approximately 5 $\mathrm{m} / \mathrm{s}$ ), true wind angle $\beta=90^{\circ}$ and ship velocity $U=10$ knots. The apparent wind speed and the apparent wind angle derive from the true wind speed $W$ and the true wind angle $\beta$ in Figure 3 as follows: 


$$
\left\{\begin{array}{l}
V^{2}=U^{2}+W^{2}+2 U W \cos \beta \\
W \sin \beta=V \sin \alpha
\end{array}\right.
$$



Figure 3.

Notattions and definitions for the true wind and apparent wind speeds and angles.

In the aforementioned conditions, the apparent wind velocity $V$ is 14 knots and the apparent wind angle $a$ is $45^{\circ}$. The thrust force delivered by the sails can be estimated using equation derived by (Babarit et. al.,2019):

$T=\frac{1}{2} \rho_{a} A_{s} V^{2}\left(C_{L} \sin a-C_{D} \cos a\right)$

where $\rho_{a}$ is the air density, $A_{s}$ is the total sail area and $C_{L}$ and $C_{D}$ are the lift and drag coefficients of the rig. For a Bermuda rig, $C_{L}$ is in the order of 1.5 and $C_{D}$ is in the order of 0.5 (Charrier, 1979). Thus, the thrust force is in the order of $470 \mathrm{~N}$. At equilibrium and without the water turbine, the thrust force is equal to the water resistance of the hull of the ship $R_{w}$. In a first approach, it is assumed that this water resistance is simply proportional to the square of the ship velocity:

$R_{w}=r_{w} U^{2}$

As the thrust force is estimated to be $470 \mathrm{~N}, \mathrm{r}_{\mathrm{w}}$ is in the order of $18 \mathrm{~N} . \mathrm{s}^{2} / \mathrm{m}^{2}$.

When the water turbine is added, it creates an additional source of drag $R_{T}$. Therefore, the ship velocity will be smaller with the water turbine than without the water turbine. According to the momentum theory, the drag force can be written:
$R_{T}=2 \rho_{w} A_{T} a(1-a) U^{2}$

Where a $\epsilon\left[0, \frac{1}{2}\right]$ is the axial induction factor, $\rho_{w}$ is the water density and $A_{T}$ is the turbine disk area. The produced power can be written:

$P_{T}=R_{T}(1-a) U$

At equilibrium, the thrust force is equal to the water resistance plus the drag force from the water turbine:

$T=R_{W}+R_{T}$

Using Equations 1, 2 and 6 it leads to an equation relating the ship velocity to the water turbine drag:

$$
\begin{gathered}
\frac{1}{2} \rho_{a} A_{s}\left(U^{2}+W^{2}+2 U W \cos \beta\right)\left(C_{L} \sin a-C_{D}\right. \\
\cos a)=r_{w} U^{2}+2 \rho_{w} A_{T} a(1-a) U^{2}
\end{gathered}
$$

Using equations 7 and 5 one can calculate the ship velocity and produced power as function of the axial induction factor. Results of such calculation are shown in Figure 4 for a true wind speed of 10 knots and a true wind angle of $90^{\circ}$. Note that in this calculation, it was assumed that the diameter of the water turbine is $240 \mathrm{~mm}$. One can see that, as expected, the ship velocity reduces with increasing induction factor (because of increasing turbine drag force).

For the produced power, one can see that a maximum of approximately $500 \mathrm{~W}$ is obtained for an optimal induction factor of approximately 0.25 . The corresponding turbine drag is approximately $200 \mathrm{~N}$ and the corresponding ship velocity is approximately 8 knots. Therefore, the cruising 600 hydrogenerator by Watt \& Sea was selected as it matches well the requirements for the test platform. Indeed, this hydrogenerator has a nominal power of $600 \mathrm{~W}$ as shown in Figure 5. It can be fitted with a turbine of diameter $240 \mathrm{~mm}$. For that turbine, it can deliver approximately $300 \mathrm{~W}$ electric power for $4 \mathrm{~m} / \mathrm{s}$ ship velocity. 

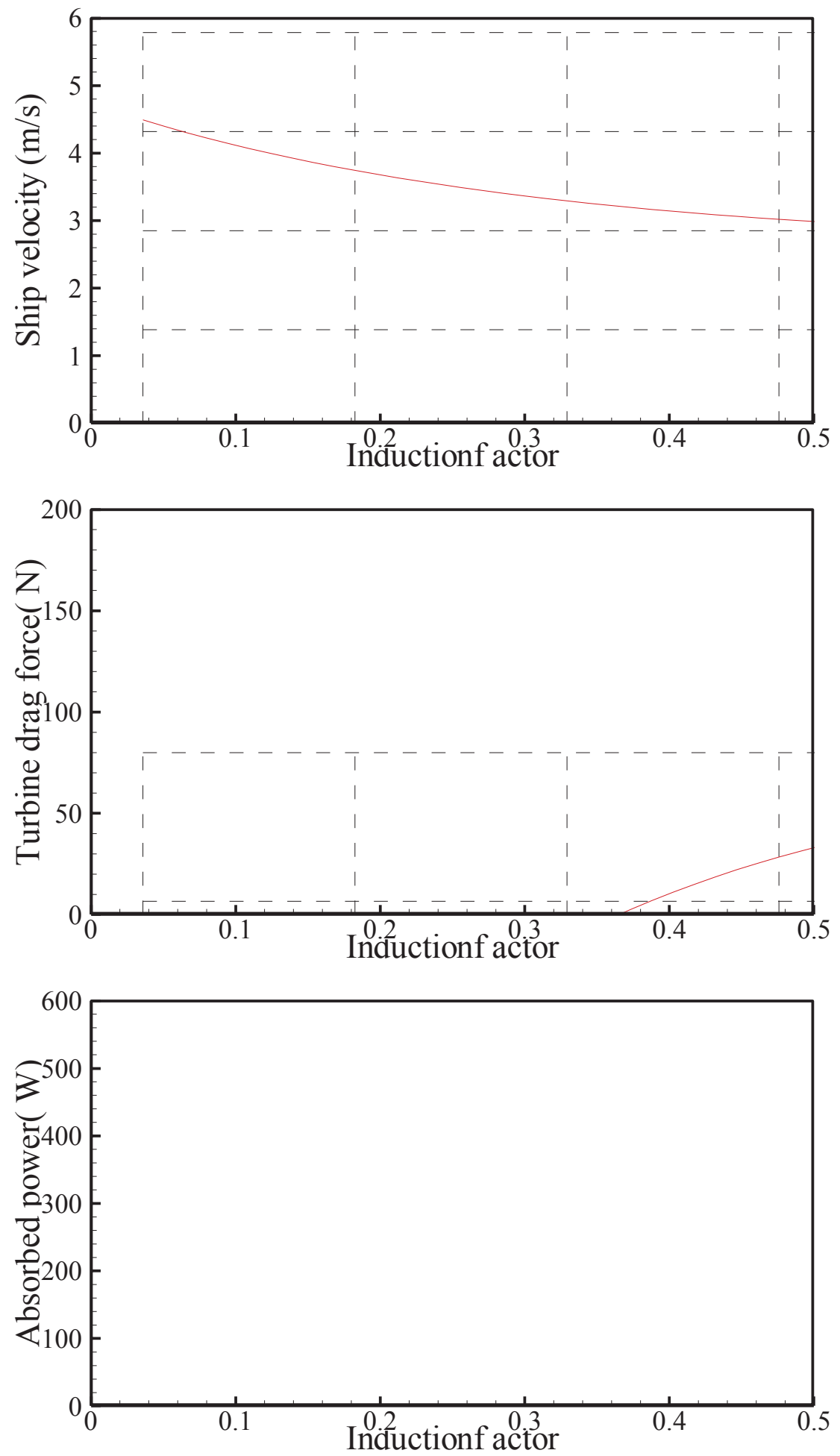

Figure 4

Ship velocity, turbine drag force and absorber power as function of the induction factor for a true wind speed of 10 knots and a true wind angle of $90^{\circ}$. 


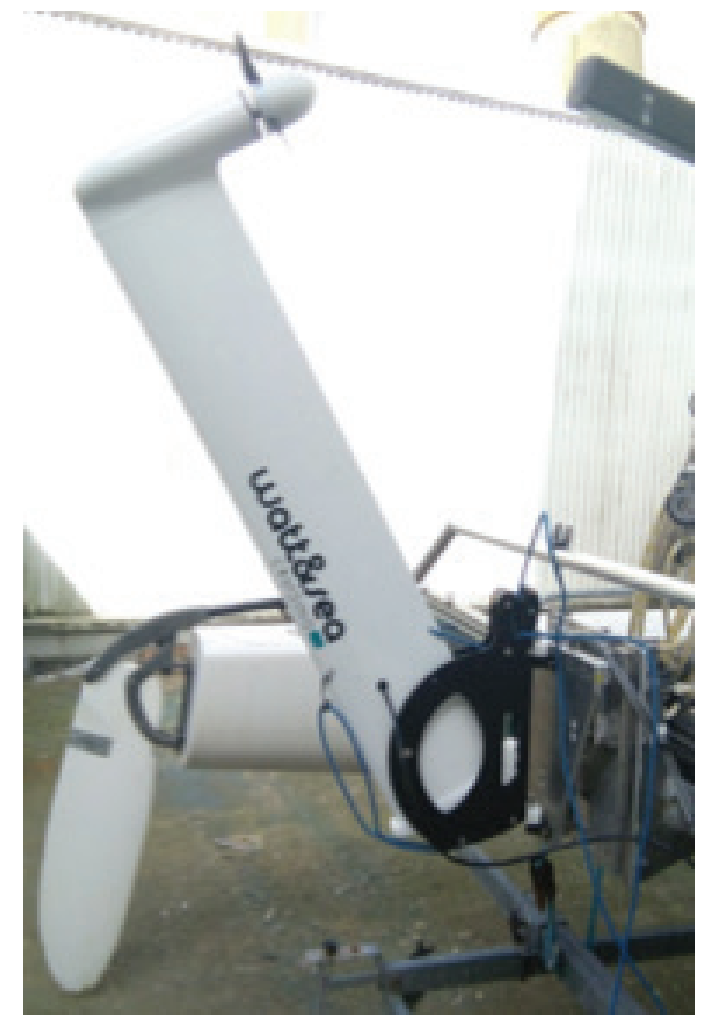

Figure 5.

Watt \& Sea cruising 600 hydrogenerator.


Figure 6.

Installation of speed sensor.

Motions of the ship were captured by BNO055IMU sensor at $100 \mathrm{~Hz}$ sampling rate. This sensor measured the heading, pitch and roll of the ship. IMU is calibrated for the best performance before conducting any test. 


\subsubsection{Wind Velocity and Direction Measurement}

For measuring wind speed and direction, an anemometer model CV7-LCJ Capteurs was mounted at the top of the mast with additional position sensor from Honeywell. This position sensor is placed at the bottom of the mast for wind direction correction. The current designed allows the mast to be rotated at 90 degrees to the port and starboard respectively. Due to the angle limitation of current position sensor, an additional method is used to limit the rotation of the mast approximately 15 degrees to the port and starboard respectively by tying the mast to the sail rig adjuster on the port and starboard side of the ship.

\subsubsection{Drag Force Sensor}

One of the objective in the experiment is to investigate the effect of the drag force in order to maximise the energy production. So it requires that force to be measured. For that purpose, a dedicated balance has been designed. It is based on a set of three strain gauges which enables the drag force in the $x$ direction as well as the moments in the $y$ and $z$ directions to be measured as shown in Figure 7. Load cell from HBM Z6 was selected for this task with triangular shape because of robustness and withstands extreme mechanical stress and aggressive media. For this purposes, 2 unit of load cell with maximum load $100 \mathrm{~kg}$ and 1 unit of load cell with maximum load $50 \mathrm{~N}$ were selected. The

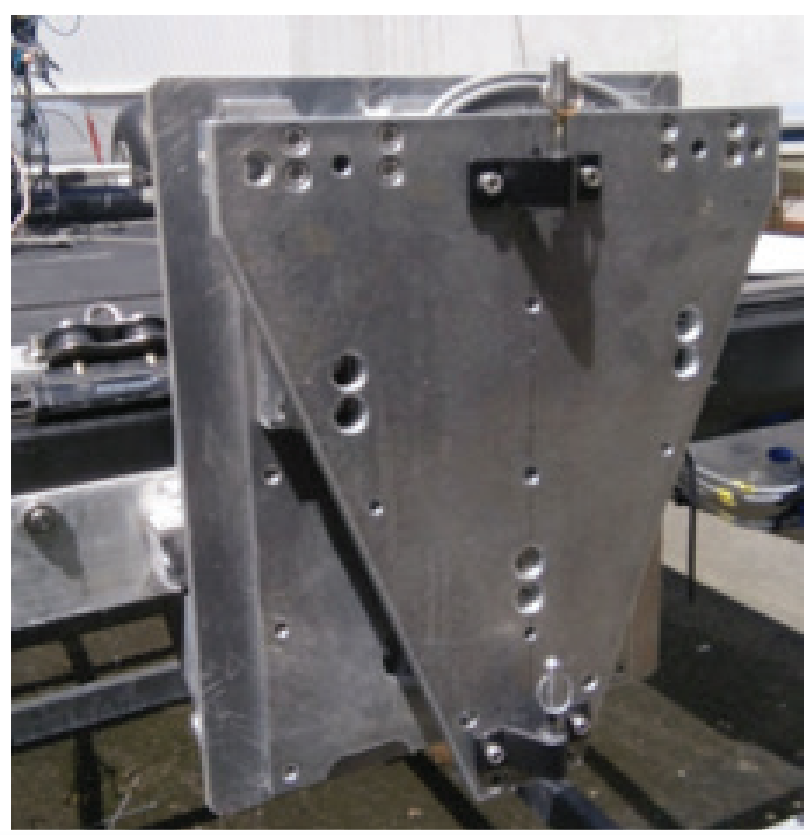

Figure 7.

Triangular load cell balance. balance is attached to the Hobie Cat Tiger at the center back of the platform. The load cells presented a linearity and hysteresis ideal for the test with error below $0.1 \%$ of the vertical and $0.4 \%$ horizontal for a full scale (200 N).

\subsubsection{Hydrogenerator and Power Management System}

For reasons explained above, a Watt \& Sea Cruise 600 hydrogenerator was selected for the test platform. This type of hydrogenerator is designed to produce high performance output during cruising with low drag profile. Cruising hydrogenerator is light, robust, compact and easy to install. Delivered with 240 $\mathrm{mm}$ propeller, power converter regulator and lifting fastening bracket. There are three different sizes of propeller available which are $200 \mathrm{~mm}, 240 \mathrm{~mm}$ and $280 \mathrm{~mm}$. Increase the propeller size can generate more power at lower speed. As an example, a $240 \mathrm{~mm}$ diameter propeller provides maximum using speed at 14 knots meanwhile propeller with larger diameter $280 \mathrm{~mm}$ provides maximum using speed at 11 knots. Lower pitch will provide better acceleration and higher pitch will provide higher top speed. The hydrogenerator also comes with variable rotational speed control function (pitch control). For getting maximum performance the rotor speed must vary with wind speed.

The hydrogenerator is operated with a power management system consist of a power converter, a 24V Lithium battery, a dump load and an Arduino NANO microcontroller as shown in Figure 8 . The $24 \mathrm{~V} 15 \mathrm{Ah}$ battery is selected due several reasons such as light weight $(3 \mathrm{~kg})$, longest life, produced constant power, fast charging and safe. The dimension of the battery is $330 \mathrm{~mm}$ in length, $96 \mathrm{~mm}$ in width and $104 \mathrm{~mm}$ in height. The alternating current electricity produced by the turbine is converted into direct current by the converter and stored into the $24 \mathrm{~V}$ Lithium battery. The converter also enables to control the water turbine (rotational velocity, drag force, power absorption) The system includes sensors for measuring the produced energy (current, voltage, power) and the turbine rotational velocity. When the battery is fully charged, the excess energy can be dissipated by the dump load.

Note that the battery included in the hydrogenerator system is also used for powering the anemometer, the data acquisition system and the wifi antenna using power over ethernet (PoE). The voltage is stepped down to $5 \mathrm{~V}$ by using buck regulators.

The hydroelectric generator component specification and function are summarized in Table 2. Power management system is located at the starboard side of the hull. Some alteration and modification need to be made at the starboard hull of the catamaran to allow compartment with waterproof hatch to be installed. Waterproof hatch on the starboard hull of the catamaran is designed to locate a few items such as Lithium battery and also dump load resistor. 




Figure 8.

Hydrogenerator and power management system.

Note that the battery included in the hydrogenerator system is also used for powering the anemometer, the data acquisition system and the wifi antenna using power over ethernet (PoE). The voltage is stepped down to $5 \mathrm{~V}$ by using buck regulators.

The hydroelectric generator component specification and function are summarized in Table 2. Power management system is located at the starboard side of the hull. Some alteration and modification need to be made at the starboard hull of the catamaran to allow compartment with waterproof hatch to be installed. Waterproof hatch on the starboard hull of the catamaran is designed to locate a few items such as Lithium battery and also dump load resistor.

Table 2.

Hydrogenerator and power management system.

\begin{tabular}{ll} 
Item & Function \\
\hline Hydrogenerator & Convert kinetic energy into electric energy \\
\hline Converter & Convert 3 phase 40 voltage into 24V DC voltage \\
\hline USB cable & As an interface to change the drag of the hydroelectric generator \\
\hline Battery & Store the renewable energy and also act as a buffer \\
\hline Dump load resistor & If the battery is in fully charged condition then the heat sink will be operated to discharge the energy \\
\hline
\end{tabular}




\subsubsection{Data acquisition system and control}

The data acquisition system is based on a Raspberry Pi 3 . It is installed onboard in a Pelicase as in Figure 9. It is connected to the various system, sensors and transducers as illustrated in Figure 10. The sensors were selected to be wired connection. Waterproof pin connectors with IP68 standard were used for the connection. Several communication protocols such as NMEA $183, I^{2} C$, ethernet and USB have been used in developing data acquisition system. As an example, GPS, anemometer and hydroelectric generator were connected using USB protocol meanwhile sensor such as IMU was connected using $\mathrm{I}^{2} \mathrm{C}$ protocol.



Figure 9.

Data acquisition system in pelicase box.

The data acquisition system has been designed to record the measured data and store it in a CSV file. The overall recorded data is simplified as listed in Table 3. Data acquisition is start and stop by pressing the corresponding buttons located on the top of the pelicase box.

Moreover, the data acquisition system has been designed to enable the live data streaming through wifi. Thus, the data can be visualized live on a remote computer by an operator located on-land or on another boat. This feature has been developed to reduce the workload of the catamaran crew, as it is expected that they will be fully busy with the navigation and operation of the boat.

Table 3.

Data variable recorded.

\begin{tabular}{ll} 
Data & Sensor \\
\hline Latitude & BU-353S4-USB GPS \\
\hline Longitude & BU-353S4-USB GPS \\
\hline Heading & BU-353S4-USB GPS / BNO055- \\
\hline IMU
\end{tabular}




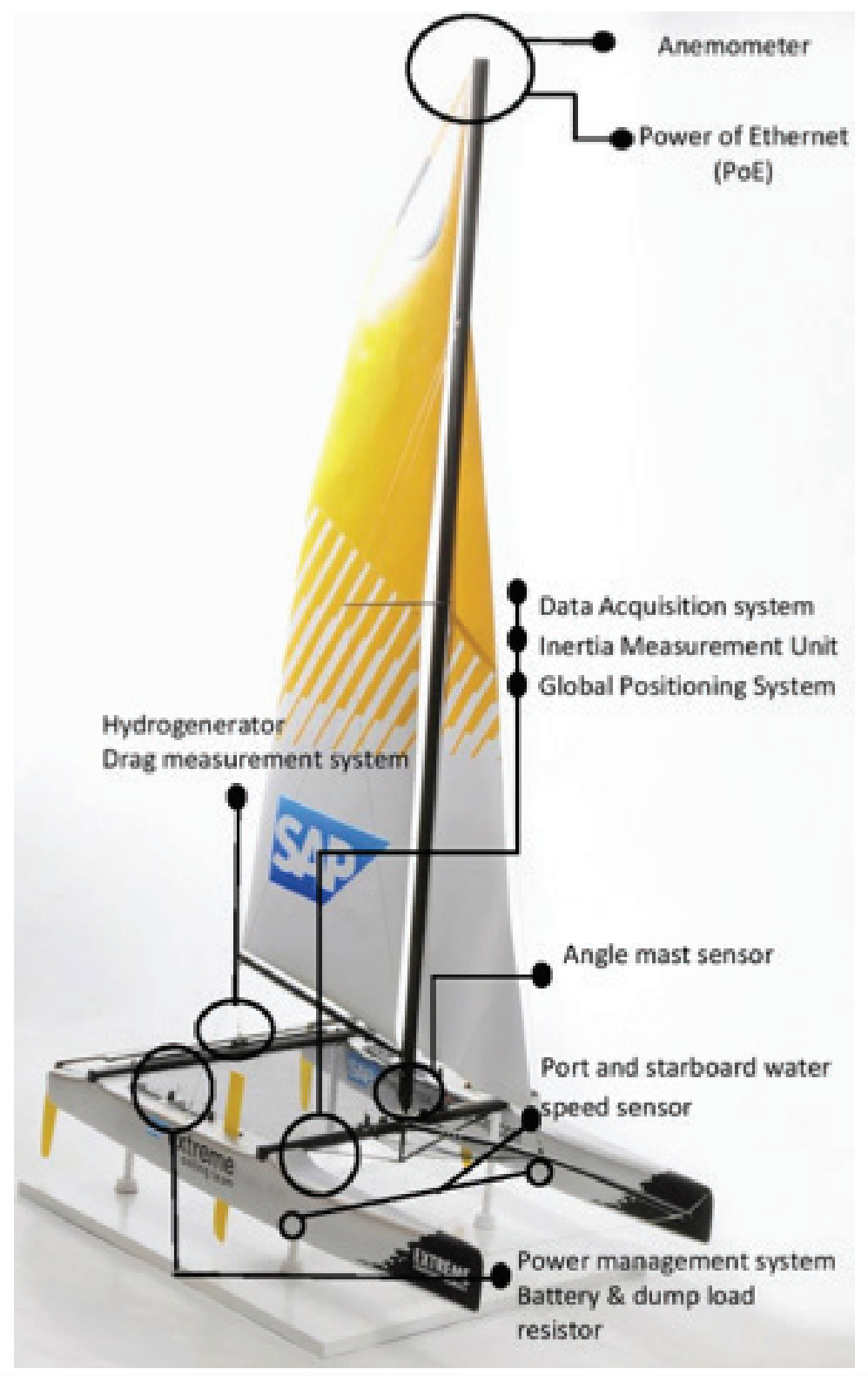

Figure 10.

Illustration of sensors location.

\section{RESULT AND DISCUSSION}

Four test was conducted to check the workability of the energy ship system and the platform as well as the data acquisition system and labelled as Run02, Run03 and Run04. A few results of trajactory of energy ship and speed can be visualised in Figure 11 and Figure 12. The trials were carried out in light wind conditions (1 to $7 \mathrm{~m} / \mathrm{s}$ ), without current. The control setting of the hydro generator was modified in order to study its effect on production energy. The hydro generator was controlled remotely, allowing the crew to focus on navigating the sailing ship. 




Figure 11.

Example of ship trajectory and speed measured during the trial. The colors indicate the speed of the sailing ship. Background and map image using Google Earth.

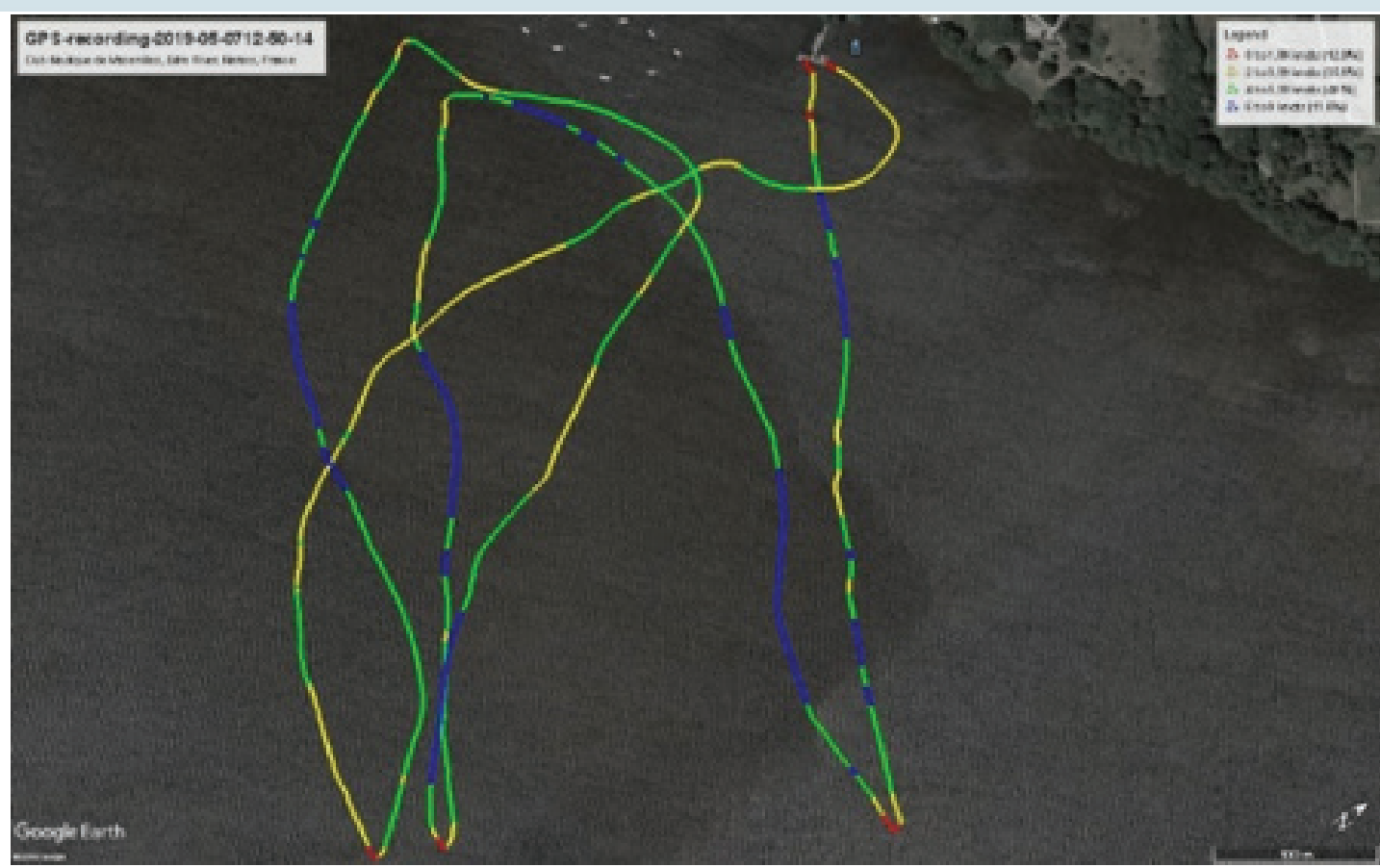

Figure 12.

Example of ship trajectory and speed measured during the trial. The colors indicate the speed of the sailing ship. Background and map image using Google Earth. 
Sample of parameters recorded during the test by the data acquisition system can be visualized in Figure 13. Figure 13 (a) shows the ship trajectory with different hydrogenator control setting meanwhile Figure 13 (b) represents the ship speed during the testing which depended on the speed of the wind. Higher wind speed will produce higher ship speed. More number of satellites will produce more accurate data and this can be viewed in Figure 13 (c). Overall, seven satellite signals were captured during the testing. Figure 13 (d) shows the direction of the

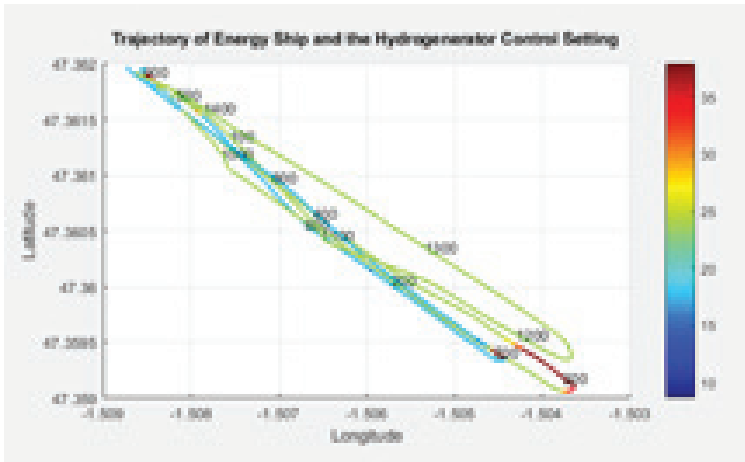

a) Longitude and Latitude

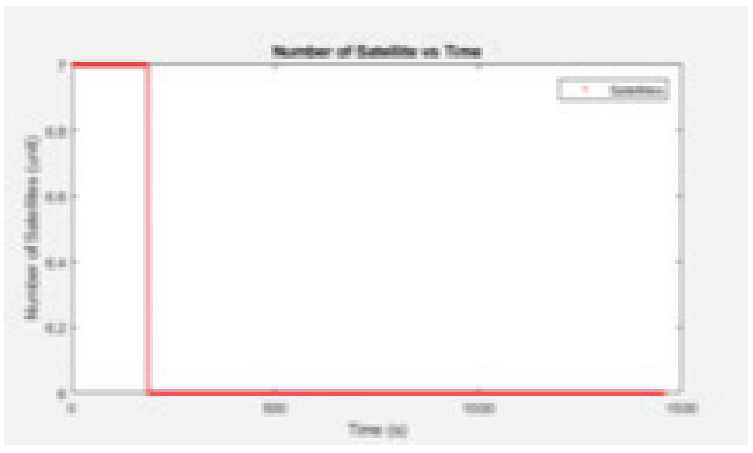

c) Number of satellite

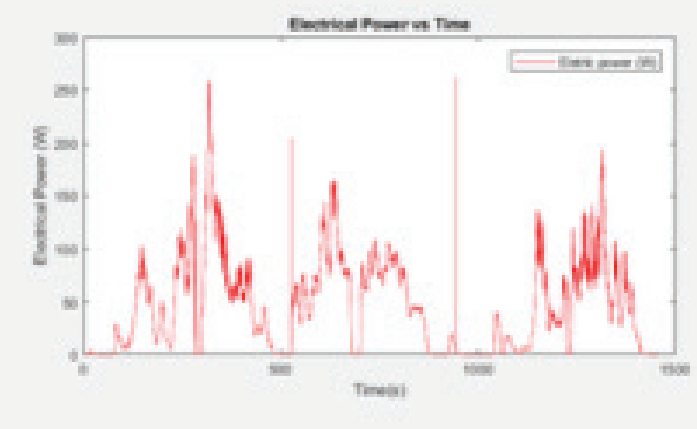

e) Hydrogenerator Power sailing ship which were in line the position of the ship that was mentioned earlier in 13 (a). Figure 13 (e) and (f) show the reading of hydrogenator power and battery voltage of the energy ship respectively that correlated with the wind speed. Other than that, Figure $13 \mathrm{~g}$ ) represents the corrected wind direction which was adjusted by mast angle sensor throughout the testing. The wind speed influences the speed of the ship and the electrical power production of the energy ship as shown in Figure 13 (h).

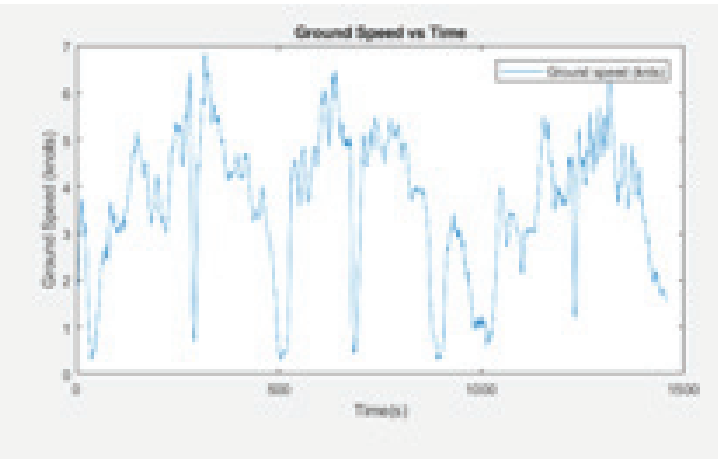

b) Boat Speed



d) Heading

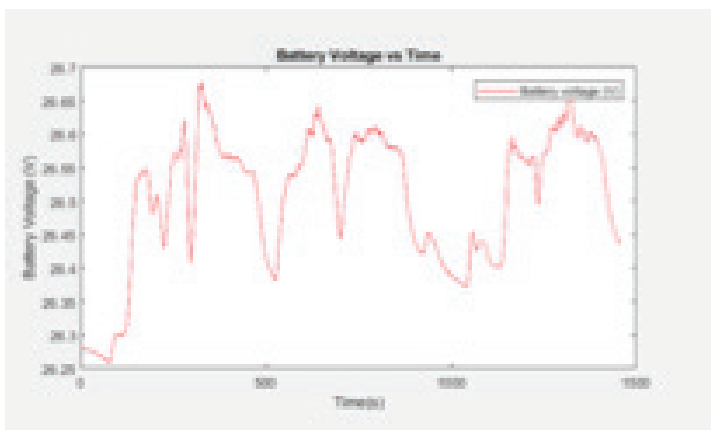

f) Battery voltage 


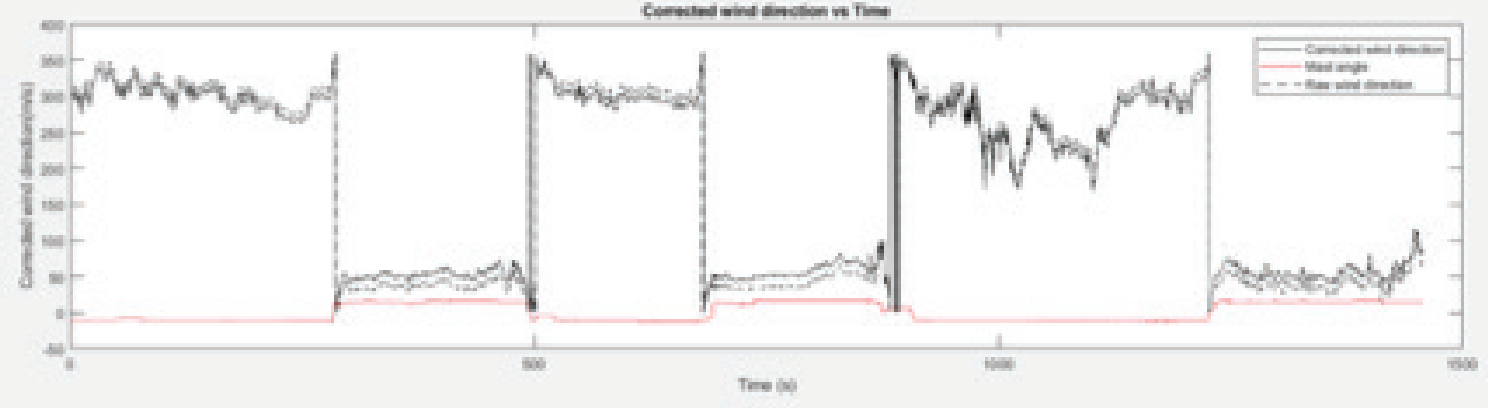

g) Wind direction

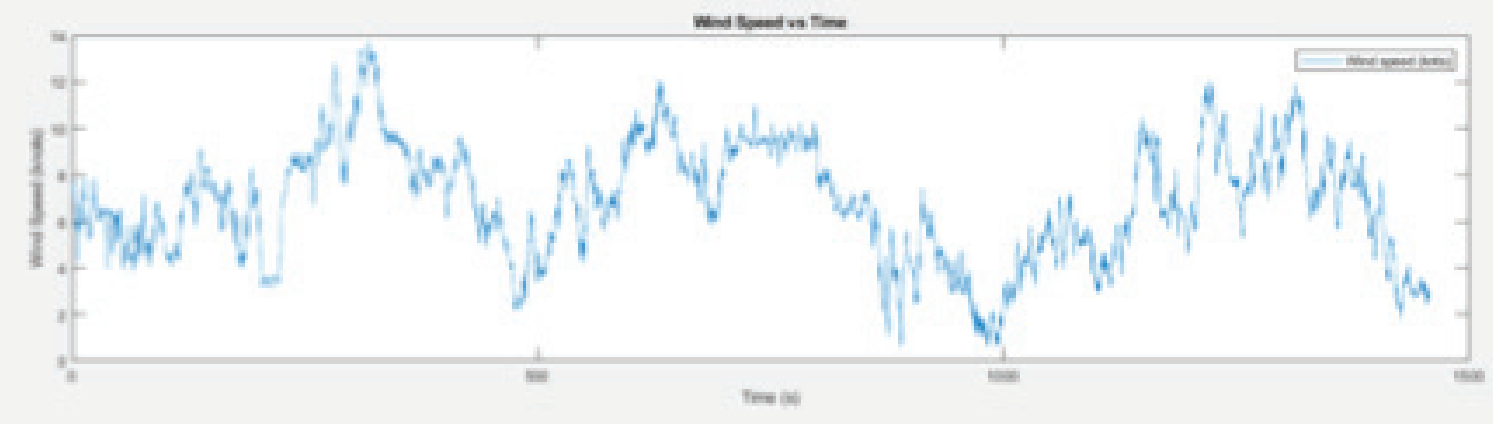

h) Wind speed

Figure 13.

Sample of parameters recorded by data acquisition system.



Figure 14.

(SOG) versus wind (TWS), with Hydro generator in operation ( $S O G \approx 0.5110$ X TWS + 0.5738). 
Figure 14 represents the average speed of the energy ship in function of the average true wind speed and the voltage of the hydro generator. The average wind speed over the data ranges selected ranged between 2.5 and $5.0 \mathrm{~m} / \mathrm{s}$. Note that a good approximation of the ship's speed is half of the real wind when the hydro generator is in operation. The formula given in Figure 14 can be used to estimate the speed of a ship and subsequently estimate the electrical power produced by an energy ship as shown in Figure 5.

\section{CONCLUSION}

This trial campaign successfully demonstrates the principle of energy ship or wind powered vessel. The amount of power that can be produced by this prototype is about 600W for the true wind speed, $11 \mathrm{~m} / \mathrm{s}$. Results obtained prove that an energy ship concept is able to produce significant amount of energy. For future studies, the usage of control pitch propeller and bigger diameter of propeller are proposed to be investigated.

\section{ACKNOWLEDGEMENT}

Highest appreciation for Dr Aurelien Babarit for knowledge sharing and guidance, LHEAA, Ecole Central Nantes, Naval Group and National Defence University of Malaysia for the sponsorship my studies in ECN.

\section{REFERENCES}

Babarit, A., Clodic, G. and Gilloteaux J-C., 2019. A new energy system for sustainable methanol production from the far-offshore wind energy resource.
Babarit, A., et al., 2020. Validation experimentale du principe du voilierhydrolienne pour la recuperation de l'energie du vent en haute mer. Proceedings of 17emes Journees De L'hydrodynamique JH2020,Cherbourg, 24-26 November 2020.

Charrier, B., 1979. Etude theorique et experimental de l'effet Magnus destine a la propulsion des navires. PhD thesis, Universite de Paris VI. (In French).

Gilloteaux, J.-C. \& Babarit, A., 2017. Preliminary Design of a Wind Driven Vessel Dedicated to Hydrogen Production. Volume 10: Ocean Renewable Energy. Available at: http://dx.doi.org/10.1115/omae2017-61408.

Gizara, A.R., 2007. Turbine integrated hydrofoil. Patent US2007/0046028A1.

Hydrodynamic in Advance Sailing Design, 1997. Twenty-First Symposium on Naval Hydrodynamics. Available at: http://dx.doi.org/10.17226/5870.

ITTC, 2014. General guidelines for uncertainty in resistance tests. ITTCRecommended procedures 7.5-02-02-02.

Kim, J. \& Park, C., 2010. Wind power generation with a parawing on ships, a proposal. Energy, 35(3), pp.1425-1432. Available at: http://dx.doi.org/10.1016/j.energy.2009.11.027.

Meller, M., 2006. Wind powered linear motion hydrogen production systems. Patent US7416918B2.

Ouchi, K. \& Henzie, J., 2017. Hydrogen generation sailing ship: Conceptual design and feasibility study. OCEANS 2017 - Aberdeen. Available at: http://dx.doi.org/10.1109/oceanse.2017.8084808.

Pelz, P.F., Holl, M. \& Platzer, M., 2016. Analytical method towards an optimal energetic and economical wind-energy converter. Energy, 94, pp.344-351. Available at: http://dx.doi.org/10.1016/j.energy.2015.10.128.

Roshamida, A.J. et al., 2019. Comparison of the capacity factor of stationary wind turbines and weather-routed energy ships in the far-offshore. EERA Deepwind 2019, Trondheim Norway.

Solomon, R.E., 1982. Process of converting wind energy to elemental hydrogen and apparatus therefor. US Patent 4335093A. 